\title{
Recomendação e uso de produtos fluoretados por cirurgiões-dentistas de um município da Bahia, Brasil
}

\author{
Recommendation and use of fluorethed products by dentists in a city of \\ Bahia, Brazil \\ Recomendación y uso de productos fluoretados por dentistas de un municipio \\ da Bahia, Brazil \\ Gabriel Bastos TEIXEIRA ${ }^{1}$ \\ Fábio Silva de CARVALHO ${ }^{2}$ \\ Cristiane Alves Paz de CARVALHO ${ }^{3}$ \\ ${ }^{1}$ Cirurgião-Dentista pela Universidade Estadual do Sudoeste da Bahia - UESB, Departamento de Saúde I, \\ Curso de Odontologia, 45208-409 Jequié-BA, Brasil \\ ${ }^{2}$ Doutor em Ciências da Saúde, Professor Adjunto da Universidade Estadual do Sudoeste da Bahia - UESB, \\ Departamento de Saúde I, Curso de Odontologia, 45208-409 Jequié-BA, Brasil \\ ${ }^{3}$ Doutora em Ciências da Saúde, Professora Adjunta da Universidade Estadual do Sudoeste da Bahia - UESB, \\ Departamento de Saúde I, Curso de Odontologia, 45208-409 Jequié-BA, Brasil
}

\begin{abstract}
Resumo
Objetivos: Investigar os critérios para a recomendação e utilização de produtos fluoretados por cirurgiões-dentistas de um município baiano. Material e método: Estudo descritivo, transversal, cuja população constituiu-se dos 128 cirurgiões-dentistas com inscrição ativa no município. A coleta de dados foi realizada por meio de um questionário semiestruturado, respondido pelo próprio participante. Os dados foram tabulados em planilha do Office Excel $2016 \AA$ e foi realizada estatística descritiva. Resultados: Cerca de $98,0 \%$ dos cirurgiões-dentistas estudaram os efeitos do flúor durante a graduação e 67,8\% afirmaram que seu efeito remineralizador ocorre em qualquer idade. Apesar do gel fluoretado ser o método de uso tópico mais indicado pela maior parte dos profissionais $(58,6 \%)$, quase $67,0 \%$ desconhecem a concentração de flúor nesse produto. Aproximadamente 53,0\% não conhecem a concentração ótima de flúor nas águas de abastecimento público. Apenas 20,7\% disseram que o dentifrício fluoretado deve ser usado por pessoas de qualquer idade, a maioria $(95,4 \%)$ confirmou existir riscos na utilização de flúor e 92,0\% consideraram que crianças até os doze anos constituem grupo de risco para a fluorose dentária. Conclusões: A maior parte dos profissionais recomenda e utiliza os fluoretos considerando sua ação preventiva e terapêutica e o risco de cárie dentária. Observou-se desconhecimento ou dúvida quanto às concentrações ideais de fluoretos na água, em soluções e géis fluoretados. A maioria dos profissionais não recomenda ou tem dúvida para recomendar dentifrício fluoretado para crianças e quanto ao uso de flúor para indivíduos com fluorose.
\end{abstract}

Descritores: Flúor; Fluorose Dentária; Odontólogos.

Abstract

Objectives: Investigate the recommendation and use criteria of fluoridated products by dentists in a city of Bahia State, Brazil. Material and method: descriptive and cross-sectional study, whose population was composed of 128 dentists with active registration in the municipality. Data collect was performed using a semi-structured questionnaire, answered by the participant. The data have been tabulated in Office Excel 2016® and descriptive statistics was performed. Results: About $98.0 \%$ of dentists studied the fluorine effects during graduation and $67.8 \%$ said their remineralizing effect occurs at any age. Despite the fluoridated gel be the most recommended topical method by the dentists (58.6\%), almost $67.0 \%$ don't know the fluoride concentration in this product. Approximately $53.0 \%$ do not know the optimal concentration of fluoride in public water supplies. Only 20.7\% said fluoridated toothpaste should be used by people of any age, the majority (95.4\%) confirmed there are risks in using fluoride and $92.0 \%$ considered that children until twelve years old are the risk group for dental fluorosis. Conclusions: the majority of the dentists recommend and use fluorides considering its preventive and therapeutic action and the risk of tooth decay. There was unfamiliarity or doubt upon the optimal concentrations of fluoride in water, mouthwashes, and fluoride gels. Most of the professionals do not recommend or have doubt to recommend fluoride toothpaste for children and about the use of fluoride for individuals with fluorosis. Descriptors: Fluorine; Fluorosis, Dental; Dentists.

\section{Resumen}

Objetivos: Investigar los criterios para la recomendación y el uso de fluoruros por los dentistas de un municipio de Bahia. Material y método: Estudio descriptivo, transversal, cuya población se constituyó de los 128 dentistas con inscripción activa en la ciudad. La recolección de datos se realizó mediante un cuestionario semi-estructurado, respondido por el participante. Los datos fueron tabulados en Office Excel 2016® y se realizó una estadística descriptiva. Resultados: Cerca del 98,0\% de los dentistas estudiaron los efectos del y el $67,8 \%$ afirmaron que su efecto remineralizador ocurre a cualquier edad. Aunque el gel fluorado es el método de uso tópico más indicado por la mayoría $(58,6 \%)$, casi el 67,0\% desconocen la concentración de flúor en ese producto. Aproximadamente $53,0 \%$ no conocen la concentración óptima de flúor en las aguas. Sólo el 20,7\% dijo que el dentifrício fluorado debe ser utilizado por personas de cualquier edad, la mayoría $(95,4 \%)$ confirmó existir riesgos en la utilización de flúor y el 92,0\% consideró que niños hasta los doce años constituyen grupo de riesgo para la fluorosis. Conclusiones: La mayoría de los dentistas recomiendan y utilizan los fluoruros considerando la prevención, la terapéutica y el riesgo de caries. Se observó desconocimiento o duda sobre las concentraciones ideales de fluoruros en el agua, en soluciones y geles fluorados. La mayoría de los profesionales no recomiendan o tienen dudas para recomendar dentifrío fluorado para niños y en cuanto al uso de flúor para individuos con fluorosis.

Descriptores: Flúor, Fluorosis Dental; Odontólogos.

\section{INTRODUÇÃO}

Durante décadas, o Streptococcus mutans foi considerado o principal agente causador da cárie dentária e a maioria das estratégias de diagnóstico, prevenção e tratamento tiveram suas ações centradas nesse microrganismo ${ }^{1,2}$.

No entanto, a microbiota bucal humana é um ecossistema habitado por centenas de espécies bacterianas diferentes, a maioria das quais são frequentemente encontradas em indivíduos saudáveis, embora em níveis inferiores do que em sujeitos com a doença ${ }^{3}$. Esses microrganismos são residentes naturais da cavidade bucal e possuem potencial para causar a doença cárie, porém, sob condições de equilíbrio, o sistema imunológico não desencadeia uma resposta ativa contra a presença deles no corpo humano ${ }^{4}$.

Portanto, uma vez que a cárie dentária é considerada biofilme-açúcar-dependente e não possui etiologia única, torna-se evidente a necessidade de fazer com que as medidas preventivas e a forma de tratamento estejam apropriadas aos seus novos paradigmas etiológicos ${ }^{4,5}$.

Por esse motivo, grande importância é dada aos veículos capazes de disponibilizar o flúor pela via tópica ${ }^{6}$. Porém, vale ressaltar que o controle da cárie consiste, basicamente, em evitar a formação e/ou progressão das lesões cariosas pela desorganização mecânica frequente do biofilme bacteriano, especialmente através da utilização de dentifrícios 
fluoretados com concentração superior a 1000 ppmF, além de dieta não-cariogênica ${ }^{7}$.

Apesar da redução da prevalência de cárie dentária após a introdução do uso dos fluoretos tópicos, a doença ainda deve ser considerada como prioridade em muitos países ao redor do mundo ${ }^{8}$. Em algumas nações, a cárie é prevalente em grande parcela da população, enquanto em outras localidades, a doença está concentrada numa pequena parte da população, que possui elevados níveis de cárie ${ }^{8}$.

$\mathrm{Na}$ prática odontológica, é imprescindível que os profissionais tenham conhecimento da importância dos fluoretos para a prevenção e controle da cárie dentária. Adicionalmente, além de analisar o risco à cárie, a recomendação do flúor deve considerar as diversas fontes de exposição, para que o risco de desenvolvimento de fluorose dentária seja minimizado. Portanto, é necessário que os cirurgiões-dentistas saibam as concentrações dos meios de uso coletivo, individual e profissional, para que o flúor seja recomendado de forma segura e racional.

Deste modo, o presente estudo foi desenvolvido com o objetivo de investigar os critérios para a recomendação e utilização de produtos fluoretados por cirurgiões-dentistas do município de Jequié, no interior do Estado da Bahia.

\section{MATERIAL E MÉTODO}

Esta pesquisa caracteriza-se como estudo descritivo do tipo transversal, realizada no município de Jequié, cidade da região sudoeste da Bahia. A mesma foi aprovada pelo Comitê de Ética em Pesquisa da Universidade Estadual do Sudoeste da Bahia - CEP/UESB (CAEE: 43806215.4.0000.0055), além de ter sido autorizada pelos participantes, mediante $o$ preenchimento do Termo de Consentimento Livre e Esclarecido (TCLE).

Para a obtenção dos nomes e dados dos profissionais foi feito o contato com o Conselho Regional de Odontologia da Bahia (CROBA), que forneceu uma lista dos cirurgiões dentistas cadastrados no município. Segundo o CROBA, em março de 2015, existiam 151 cirurgiões dentistas inscritos no município, sendo 128 deles com a inscrição ativa.

Desses 128 cirurgiões dentistas com inscrição ativa no município, foram excluídos da pesquisa os cirurgiões dentistas envolvidos no estudo (dois profissionais), os cirurgiões dentistas que foram encontrados, mas que não exercem a profissão (sete profissionais), os cirurgiões dentistas que se recusaram a participar da pesquisa (oito profissionais) e, por fim, os cirurgiões dentistas que não realizam atendimento no município ou não puderam ser localizados (24 profissionais). Desse modo, a amostra final totalizou um número de 87 cirurgiões dentistas.

A coleta de dados foi feita a partir de um questionário semiestruturado elaborado pelos pesquisadores e adequado ao objeto de estudo, que permitiu a identificação dos participantes, bem como a idade, o sexo e a formação profissional. Posteriormente, permitiu verificar os critérios utilizados para a recomendação e uso do flúor, bem como o conhecimento dos profissionais a respeito das indicações, métodos de aplicação, concentrações, toxicidade e meios de acesso ao flúor. $\mathrm{O}$ questionário foi entregue pessoalmente pelo pesquisador e este foi respondido pelo próprio participante, permitindo que ele se expressasse livremente sem qualquer interferência. Os dados foram tabulados em planilha do programa Office Excel 2016®. Foi realizada estatística descritiva baseada em proporções e frequências absoluta e relativa simples para a análise dos resultados.

\section{RESULTADOS}

A amostra final constituiu-se, em relação ao sexo, por maioria feminina (Tabela 1) e a média de idade dos participantes foi de 36,4 anos. A proporção entre aqueles com mais de dez anos de conclusão da graduação e aqueles com menos de dez anos de conclusão foi semelhante (Tabela 1). A maioria dos participantes da pesquisa se formou em faculdades públicas $(65,5 \%)$, fez a graduação na Bahia $(56,3 \%)$ e possui algum tipo de especialização $(63,2 \%)$ (Tabela 1). Praticamente todos os dentistas receberam alguma informação sobre o uso profilático e terapêutico do flúor durante o período da graduação $(97,7 \%)$ (Tabela 1).

Para aproximadamente $59,0 \%$ dos entrevistados, o produto de escolha é o flúor em forma de gel, sendo que o creme dental só é lembrado por 9,2\% dos profissionais. Além disso, cerca de $22,0 \%$ dos entrevistados recomendaram o uso de flúor em casos de risco de cárie, sendo que o risco à cárie ainda foi associado à idade em $13,8 \%$ e à sensibilidade em $9,2 \%$ das respostas. Aproximadamente $22,0 \%$ dos entrevistados recomendaram o flúor como forma de prevenir o aparecimento da cárie dentária, sem qualquer outro critério associado. Os dados relativos ao conhecimento dos cirurgiões dentistas acerca dos efeitos do flúor podem ser encontrados na Tabela 2. No que diz respeito à fluoretação das águas de consumo e à presença de fluoretos nos alimentos, os dados estão apresentados na Tabela 3.

Tabela 1. Caracterização dos cirurgiões dentistas por sexo, formação acadêmica e pós-graduação. Jequié, Bahia, Brasil, 2015

\begin{tabular}{lcc}
\hline Variável & n & \% \\
\hline Sexo & & \\
Masculino & 38 & 43,7 \\
Feminino & 49 & 56,3 \\
Conclusão da graduação & & \\
Mais de 10 anos & 43 & 49,4 \\
Menos de 10 anos & 44 & 50,6 \\
Formação & & \\
Universidade Pública & 57 & 65,5 \\
Universidade Privada & 30 & 34,5 \\
Local de Graduação & & \\
AL & 2 & 2,3 \\
AM & 1 & 1,1 \\
BA & 49 & 56,3 \\
MG & 18 & 20,7 \\
PB & 3 & 3,4 \\
RJ & 1 & 1,1 \\
SE & 5 & 5,7 \\
SP & & \\
Portugal & 7 & 8,0 \\
Pós-graduação & 1 & 1,1 \\
Não tem & & \\
Atualização & 9 & 10,3 \\
Especialização & 13 & 14,9 \\
Mestrado & 55 & 63,2 \\
Total & 10 & 11,5 \\
& 87 & 100 \\
\hline & &
\end{tabular}

Tabela 2. Conhecimento dos cirurgiões dentistas acerca do efeito preventivo e terapêutico do flúor. Jequié, Bahia, Brasil, 2015

\begin{tabular}{lrr}
\hline Variável & n & \% \\
\hline $\begin{array}{l}\text { Abordagem sobre uso do flúor } \\
\text { durante a graduação }\end{array}$ & & \\
Sim & 85 & 97,7 \\
Não & 2 & 2,3 \\
Indicação e uso do flúor & & \\
Ação Preventiva & 36 & 41,4 \\
Ação Terapêutica & 4 & 4,6 \\
Ambas & 44 & 50,6 \\
Não sabem & 3 & 3,4 \\
Mecanismo de ação do flúor & & \\
Efeito Pré-Eruptivo & 17 & 19,5 \\
Efeito Pós-Eruptivo & 67 & 77,0 \\
Não sabem & 3 & 3,4 \\
Faixa etária em que existe efeito & & \\
remineralizador & & \\
Até 06 anos & 3 & 3,4 \\
Entre 06 e 12 anos & 18 & 20,7 \\
Entre 12 e 18 anos & 2 & 2,3 \\
Qualquer Faixa Etária & 59 & 67,8 \\
Não sabem & 5 & 5,7 \\
Total & 87 & 100 \\
\hline
\end{tabular}


Tabela 3. Conhecimento dos cirurgiões dentistas acerca da fluoretação das águas de consumo e da presença de flúor nos alimentos. Jequié, Bahia, Brasil, 2015

\begin{tabular}{|c|c|c|}
\hline Variável & $\mathbf{n}$ & $\%$ \\
\hline \multicolumn{3}{|c|}{$\begin{array}{l}\text { Fluoretação da água de } \\
\text { abastecimento do município }\end{array}$} \\
\hline Sim & 67 & 77,0 \\
\hline Não & 2 & 2,3 \\
\hline Não sabem & 18 & 20,7 \\
\hline \multicolumn{3}{|c|}{$\begin{array}{l}\text { Concentração ótima de fluoreto } \\
\text { na água de consumo }\end{array}$} \\
\hline Menor que 0,7 ppm & 14 & 16,1 \\
\hline Entre 0,7 e $1,2 \mathrm{ppm}$ & 41 & 47,1 \\
\hline Maior que 1,2 ppm & 1 & 1,1 \\
\hline Não sabem & 31 & 35,6 \\
\hline \multicolumn{3}{|c|}{$\begin{array}{l}\text { Presença de flúor na água } \\
\text { mineral engarrafada }\end{array}$} \\
\hline Sim & 55 & 63,2 \\
\hline Não & 13 & 14,9 \\
\hline Não sabem & 19 & 21,8 \\
\hline \multicolumn{3}{|c|}{$\begin{array}{l}\text { Presença de flúor em alimentos } \\
\text { naturais }\end{array}$} \\
\hline Sim & 69 & 79,3 \\
\hline Não & 6 & 6,9 \\
\hline Não sabem & 12 & 13,8 \\
\hline \multicolumn{3}{|c|}{$\begin{array}{l}\text { Presença de flúor em alimentos } \\
\text { industrializados }\end{array}$} \\
\hline Sim & 70 & 80,5 \\
\hline Não & 7 & 8,0 \\
\hline Não sabem & 10 & 11,5 \\
\hline Total & 87 & 100 \\
\hline
\end{tabular}

A Tabela 4 contém informações relativas às concentrações de flúor recomendadas em alguns produtos fluoretados e a Tabela 5 contém os dados concernentes à recomendação de dentifrícios fluoretados.

Por fim, as informações acerca dos riscos na utilização do flúor podem ser encontradas na Tabela 6.

Tabela 4. Recomendação e conhecimento sobre as concentrações de fluoretos de uso tópico por cirurgiões dentistas. Jequié, Bahia, Brasil, 2015

\begin{tabular}{|c|c|c|}
\hline Variável & $\mathbf{n}$ & $\%$ \\
\hline \multicolumn{3}{|l|}{$\begin{array}{l}\text { Concentração de flúor em gel para } \\
\text { aplicação tópica }\end{array}$} \\
\hline 100 ppm & 4 & 4,6 \\
\hline 1000 ppm & 17 & 19,5 \\
\hline 5000 ppm & 8 & 9,2 \\
\hline 12000 pmm & 29 & 33,3 \\
\hline 50000 ppm & 1 & 1,1 \\
\hline Não sabem & 28 & 32,2 \\
\hline \multicolumn{3}{|l|}{$\begin{array}{l}\text { Faixa etária recomendada para } \\
\text { bochecho fluoretado }\end{array}$} \\
\hline Abaixo de 06 anos & 1 & 1,1 \\
\hline Acima de 06 anos & 72 & 82,8 \\
\hline Qualquer Faixa Etária & 7 & 8,0 \\
\hline Não sabem & 6 & 6,9 \\
\hline \multicolumn{3}{|l|}{$\begin{array}{l}\text { Concentração recomendada para } \\
\text { bochecho diário (NaF) }\end{array}$} \\
\hline 0,20\% (909 ppm) & 6 & 6,9 \\
\hline 0,05\% (227 ppm) & 37 & 42,5 \\
\hline 0,02\% (100 ppm) & 19 & 21,8 \\
\hline Não sabem & 25 & 28,7 \\
\hline \multicolumn{3}{|l|}{$\begin{array}{l}\text { Concentração recomendada para } \\
\text { bochecho semanal (NaF) }\end{array}$} \\
\hline 0,20\% (909 ppm) & 42 & 48,3 \\
\hline 0,05\% (227 ppm) & 13 & 14,9 \\
\hline 0,02\% (100 ppm) & 5 & 5,7 \\
\hline Não sabem & 27 & 31,0 \\
\hline \multicolumn{3}{|l|}{$\begin{array}{l}\text { Frequência recomendada } \\
\text { aplicação de verniz }\end{array}$} \\
\hline 1 vez por ano & 24 & 27,6 \\
\hline 2 a 4 vezes por ano & 36 & 41,4 \\
\hline Mais de 4 vezes por ano & 6 & 6,9 \\
\hline Não sabem & 20 & 23,0 \\
\hline Sem Resposta & 1 & 1,1 \\
\hline Total & 87 & 100 \\
\hline
\end{tabular}

Tabela 5. Recomendação de dentifrícios fluoretados por cirurgiões dentistas. Jequié, Bahia, Brasil, 2015

\begin{tabular}{|c|c|c|}
\hline Variável & $\mathbf{n}$ & $\%$ \\
\hline \multicolumn{3}{|l|}{$\begin{array}{l}\text { Faixa etária recomendada para } \\
\text { dentifrício fluoretado }\end{array}$} \\
\hline Acima de 04 anos & 29 & 33,3 \\
\hline Acima de 06 anos & 34 & 39,1 \\
\hline Qualquer Faixa Etária & 18 & 20,7 \\
\hline Não sabem & 5 & 5,7 \\
\hline \multicolumn{3}{|l|}{$\begin{array}{l}\text { Recomendação da quantidade } \\
\text { aproximada para crianças }\end{array}$} \\
\hline Grão de Arroz & 61 & 70,1 \\
\hline Grão de Feijão & 24 & 27,6 \\
\hline Não sabem & 2 & 2,3 \\
\hline \multicolumn{3}{|l|}{$\begin{array}{l}\text { Recomendação da quantidade } \\
\text { aproximada para adultos }\end{array}$} \\
\hline Grão de Arroz & 8 & 9,2 \\
\hline Grão de Feijão & 70 & 80,5 \\
\hline Toda Extensão da Escova Dental & 7 & 8,0 \\
\hline Não sabem & 2 & 2,3 \\
\hline \multicolumn{3}{|l|}{$\begin{array}{l}\text { Concentração recomendada até } 6 \\
\text { anos }\end{array}$} \\
\hline Sem Flúor & 43 & 49,4 \\
\hline 500 ppm & 16 & 18,4 \\
\hline Entre 500 e 1000 ppm & 8 & 9,2 \\
\hline Entre 1000 e 1500 ppm & 9 & 10,3 \\
\hline Não sabem & 11 & 12,6 \\
\hline \multicolumn{3}{|l|}{$\begin{array}{l}\text { Concentração recomendada acima } \\
\text { de } 6 \text { anos }\end{array}$} \\
\hline Sem Flúor & 3 & 3,4 \\
\hline 500 ppm & 10 & 11,5 \\
\hline Entre 500 e 1000 ppm & 25 & 28,7 \\
\hline Entre 1000 e 1500 ppm & 31 & 35,6 \\
\hline Não sabem & 18 & 20,7 \\
\hline \multicolumn{3}{|l|}{$\begin{array}{l}\text { Concentração recomendada para } \\
\text { adultos }\end{array}$} \\
\hline Sem Flúor & 2 & 2,3 \\
\hline 500 ppm & 1 & 1,1 \\
\hline Entre 500 e 1000 ppm & 8 & 9,2 \\
\hline Entre 1000 e 1500 ppm & 58 & 66,7 \\
\hline Não sabem & 18 & 20,7 \\
\hline Total & 87 & 100 \\
\hline
\end{tabular}

Tabela 6. Conhecimento dos cirurgiões dentistas acerca dos riscos decorrentes do uso inadequado dos fluoretos. Jequié, Bahia, Brasil, 2015

\begin{tabular}{lrr}
\hline Variável & n & \% \\
\hline $\begin{array}{l}\text { Existência de risco de intoxicação } \\
\text { pelo flúor }\end{array}$ & & \\
Sim & 83 & 95,4 \\
Não & 1 & 1,1 \\
Não sabem & 3 & 3,4 \\
Faixa etária de risco para adquirir & & \\
fluorose dentária & & \\
Abaixo de 12 anos & 80 & 92,0 \\
Qualquer Faixa Etária & 5 & 5,7 \\
Não sabem & 2 & 2,3 \\
Recomendação de uso de flúor para & & \\
pessoas com fluorose & & \\
Sim & 43 & 49,4 \\
Não & 36 & 41,4 \\
Não sabem & 8 & 9,2 \\
Total & 87 & 100 \\
\hline
\end{tabular}

\section{DISCUSSÃO}

A coleta de dados desse estudo revelou que existe grande diferença entre os registros oficiais do Conselho Regional de Odontologia da Bahia e a realidade de atendimento odontológico no município de Jequié. Alguns profissionais inscritos em outros municípios também realizam atendimento na cidade e outros não atualizam seu cadastro quando não atuam mais no local ou quando não realizam mais atividades como dentista.

A pesquisa mostrou que poucos dentistas permanecem sem realizar algum tipo de pós-graduação. Os cursos de especialização foram os mais procurados pelos profissionais, 
demonstrando grande interesse pela busca de aperfeiçoamento técnico e científico para lacunas deixadas durante a graduação.

Durante a primeira metade do século $\mathrm{XX}$, os primeiros conceitos acerca do efeito preventivo do flúor definiam que o íon possuía a capacidade de fortalecer a estrutura dentária quando consumido pelo indivíduo durante o período de formação dos dentes, ou seja, os dentes se tornariam resistentes à cárie devido à incorporação definitiva do flúor na estrutura do esmalte ${ }^{9}$. No entanto, verificou-se que o mecanismo pelo qual o flúor confere maior resistência ao esmalte dentário ocorre em sua superfície, ao longo de toda a vida, por meio de consecutivos episódios de desmineralização e remineralização ${ }^{6}$. É válido salientar que o fluoreto não é capaz de evitar a formação de biofilme na superfície dentária ${ }^{9}$, mas a sua presença nos fluidos orais inibe a desmineralização ${ }^{10}$.

Portanto, não restam dúvidas de que o conhecimento acerca da utilização dos fluoretos como estratégia para prevenção e tratamento da doença cárie, em qualquer idade, é de grande relevância para a atualidade. Pesquisa realizada por Pakdaman et al. ${ }^{11}$ avaliou o conhecimento de dentistas acerca do uso e recomendação do flúor na cidade de Teerã e mostrou que apenas $39,2 \%$ dos participantes consideravam útil o uso do flúor em adolescentes e adultos. Esses dados sinalizam que, mesmo com a exaustiva divulgação científica dos mecanismos de ação do flúor, ainda persistem atitudes equivocadas por parte de alguns profissionais quanto à sua recomendação na rotina de atendimento.

Nesse estudo, cerca de $45 \%$ dos cirurgiões dentistas considerou o risco à cárie como fator determinante para recomendação do flúor, mas somente $13,8 \%$ deles associaram o risco de cárie à idade do paciente e ainda 21,8\% consideraram apenas a prevenção, sem qualquer menção a algum fator de risco associado. É necessário salientar que o dentista deve estar atento às múltiplas fontes de exposição ao flúor, uma vez que sua indicação também depende desse tipo de informação.

Yoder et al. ${ }^{12}$ conduziram um estudo que avaliou o conhecimento de dentistas e técnicos do Estado de Indiana, nos Estados Unidos, acerca do modo de ação dos fluoretos e seus protocolos de uso na prevenção de cárie dentária, antes e depois da divulgação de recomendações de uso desses produtos pelo Centro de Controle e Prevenção de Doenças dos EUA (US Center for Diseases Control and Prevention). Os autores observaram que $73 \%$ dos dentistas consideravam o efeito pré-eruptivo como mecanismo de ação dos fluoretos, mesmo após a campanha governamental de utilização do flúor $^{12}$. Em contrapartida, no presente estudo apenas $19,5 \%$ dos dentistas consideraram o efeito pré-eruptivo do flúor.

Posteriormente às primeiras descobertas relacionadas aos efeitos do flúor, definiu-se que níveis adequados de flúor na água de abastecimento - em torno de $0,7 \mathrm{ppmF} / \mathrm{L}$ - são capazes de reduzir a prevalência de cárie em aproximadamente $60 \%{ }^{13}$. Pôde-se observar nesse estudo que, apesar do grande índice de concordância entre os dentistas no que diz respeito a presença de fluoretos nas águas de consumo, suas concentrações ótimas são desconhecidas pela grande maioria deles. $\mathrm{O}$ mesmo não aconteceu em um estudo realizado por Leal et al. ${ }^{14}$, onde se avaliou o conhecimento de estudantes de graduação de um curso de odontologia. Na pesquisa, os autores puderam constatar que $77,6 \%$ dos estudantes sabiam a concentração ótima de flúor presente na água ${ }^{14}$.

A fluoretação das águas é reconhecidamente eficaz, econômica e abrangente na prevenção da cárie dentária e a Organização Mundial da Saúde (OMS) segue recomendandoa como medida estratégica de saúde pública ${ }^{15}$. No Brasil, a estratégia de fluoretação das águas de abastecimento teve início em 1953, no município de Baixo Guandu, Estado do
Espírito $\operatorname{Santo}^{16}$ e, atualmente, cerca de $60 \%$ da população brasileira possui cobertura do serviço, embora com importantes desigualdades entre as regiões ${ }^{17}$. Entretanto, apesar de sua ampla recomendação, ainda existem grandes questionamentos quanto à efetividade dessa fluoretação em populações que estão expostas a múltiplas fontes de flúor ${ }^{18}$.

Em um estudo recente conduzido por Bizerril et al. ${ }^{19}$ analisou-se a presença de flúor na água comercializada em garrafas de $500 \mathrm{ml}$, distribuídas na cidade de Fortaleza, Ceará, Brasil. Os autores verificaram que as águas engarrafadas das marcas avaliadas apresentaram concentrações de flúor diferentes dos valores informados nos rótulos ${ }^{19}$. Essa irregularidade pode ser responsável por induzir a população a aumentar ou diminuir o consumo de flúor em sua dieta ${ }^{19}$. A partir dos dados do presente estudo, pôde-se verificar que $63,2 \%$ dos profissionais entrevistados reconheceram que a água engarrafada consumida no Brasil apresenta flúor em sua composição.

A literatura científica já mostrou que a maioria dos alimentos consumidos pela população possui concentrações de flúor inferiores a $0,5 \mathrm{mgF} / \mathrm{g}$, com exceção de frutos do mar e produtos à base de frango, que podem apresentar maiores níveis de flúor devido à inclusão de osso, pele e conchas durante o seu processamento ${ }^{20}$. Por outro lado, a concentração de flúor em diversas bebidas é comumente originada do íon presente na água usada durante o processo industrial ${ }^{21}$. Considera-se que o intervalo ótimo de ingestão de flúor é entre 0,05 e $0,07 \mathrm{mgF} / \mathrm{kg} / \mathrm{dia}^{22}$. Portanto, fica claro que a quantidade de flúor presente na alimentação pode contribuir com a ingestão diária total de flúor e, consequentemente, com o desenvolvimento de fluorose em crianças. Nesse estudo, verificou-se que $79,3 \%$ e $80,5 \%$ dos dentistas responderam que alimentos naturais e industrializados contém flúor em sua composição, respectivamente.

Semelhantemente à concentração ótima de flúor na água, a grande maioria dos cirurgiões dentistas não soube as concentrações adequadas de géis (12000 ppm) e bochechos fluoretados (Diário: 0,05\%, Semanal: 0,20\%), fato que chama atenção para o risco de prescrição inadequada desses produtos, podendo caracterizar casos de imperícia ou imprudência. Entretanto, a maioria dos entrevistados concordou sobre a faixa etária adequada para recomendação de tais bochechos (Acima de 06 anos), o que minimiza os possíveis riscos de intoxicação crônica ou aguda, causadas por falta de conhecimento das concentrações adequadas. Apesar da relativa falta de conhecimento acerca de tais concentrações, o flúor em gel é o produto tópico de escolha para quase $59,0 \%$ dos profissionais desse estudo. Como o creme dental foi lembrado por poucos profissionais $(9,2 \%)$, ficou claro o quanto a prática preventiva ainda é negligenciada.

A dificuldade em conhecer as concentrações ideais de compostos fluoretados também foi verificada por Yoder et al. ${ }^{12}$ que constataram que $52 \%$ dos dentistas participantes de sua pesquisa relataram não conhecer a concentração de flúor para aplicação tópica em forma de gel e apenas 17\% sabiam a concentração correta, mesmo após a campanha governamental de recomendação de uso de fluoretos. Observa-se, portanto, que o conhecimento acerca das concentrações de produtos fluoretados é amplamente negligenciado pelos dentistas.

Apesar de grande parte dos dentistas possuírem conhecimento adequado acerca da quantidade de dentifrício ideal para as diferentes faixas etárias, a maioria recomendou dentifrícios sem flúor ou com baixa concentração para crianças. O que chama atenção nesse aspecto é que a maioria dos dentistas reconheceu a concentração ideal dos dentifrícios, mas não recomendaram tal concentração para pacientes pediátricos, diferentemente do estudo de Yoder et al. ${ }^{12}$, onde os $49 \%$ dos dentistas relataram não saber a 
concentração ideal de flúor dos cremes dentais e apenas $31 \%$ sabiam a concentração corretamente, mesmo após a campanha governamental de recomendação de uso de fluoretos.

Ammari et al. ${ }^{23}$ e Walsh et al. ${ }^{24}$ concluíram em revisão sistemática que dentifrícios com baixa concentração de flúor não são eficazes na prevenção da cárie dentária em comparação com dentifrícios de concentrações iguais ou superiores a $1000 \mathrm{ppm}$. Consequentemente, torna-se fundamental evitar a ingestão de cremes dentais pelas crianças durante a escovação, ficando ao encargo dos pais ou responsáveis o controle da quantidade de dentifrício adequada para as crianças, diminuindo ao máximo o risco de fluorose em uma idade precoce.

A maior parte dos odontólogos confirmou a existência de riscos na utilização de fluoretos. A faixa etária de risco para desenvolver fluorose foi identificada corretamente pela maioria dos participantes, porém o uso de fluoretos por pacientes diagnosticados com fluorose causou divergências significantes entre as respostas. A polêmica em torno do uso do flúor por pacientes que possuem fluorose não se repete num estudo semelhante publicado por Bansal et al. ${ }^{25}$, no qual $70 \%$ dos dentistas que participaram de pesquisa afirmaram corretamente que o uso de fluoretos por pacientes com fluorose é seguro.

De fato, apesar de todos os benefícios, o elemento flúor, ainda que na forma de fluoreto, apresenta alta reatividade química, podendo produzir efeitos adversos, de forma crônica ou aguda ${ }^{26}$. Na primeira, o excesso de fluoretos circulantes no organismo afeta a mineralização dos dentes durante o período de formação dos mesmos, denominada fluorose dentária ${ }^{27}$. Zaror et al. ${ }^{28}$ constataram por meio de revisão sistemática que, com exceção da fluorose dentária, não há nenhuma associação confirmada na literatura entre a fluoretação da água e qualquer outro efeito adverso crônico.

Considerando-se que a cárie dentária é a doença humana mais prevalente, afetando de 80 a $90 \%$ da população mundial $^{29}$ e uma vez que a grande maioria dos participantes desse estudo afirmou ter recebido informações sobre o uso racional do flúor durante o período da graduação, pode-se deduzir que ainda existem dúvidas com relação a esse conteúdo, além da ausência de utilização efetiva de fluoretos na rotina de atendimento ou até mesmo a presença de equívocos associada à falta de interesse em atualizar-se a respeito de tais conhecimentos.

Ainda hoje é possível constatar que muitos dentistas continuam a priorizar a prática curativa e centrada no tratamento da doença em substituição ao modelo de prevenção e promoção de saúde bucal, que atrelado à falta de conhecimento acerca do flúor, pode resultar em prejuízos para a saúde das pessoas.

\section{CONCLUSÃO}

A maior parte dos dentistas recomenda e utiliza os fluoretos considerando sua ação preventiva e terapêutica e o risco de cárie dentária. Observou-se desconhecimento ou dúvida quanto às concentrações ideais de fluoretos na água, em soluções e géis fluoretados. A maioria dos profissionais não recomenda ou tem dúvida para recomendar dentifrício fluoretado para crianças e quanto ao uso de flúor por indivíduos com fluorose.

É necessário que os profissionais se mantenham atualizados acerca do uso racional dos fluoretos, uma vez que novas pesquisas e publicações surgem constantemente. Negligenciar o aperfeiçoamento científico acerca do flúor pode gerar impactos negativos na saúde dos pacientes.

\section{REFERÊNCIAS}

1. Plonka KA, Pukallus ML, Barnett AG, Walsh LJ, Holcombe TH, Seow WK. Mutans streptococci and lactobacilli colonization in predentate children from the neonatal period to seven months of age. Caries Res. 2012; 46(3):213-20.

2. Kt S, Kmk M, N B, Jimson S, R S. Dental caries vaccine - a possible option? J Clin Diagn Res. 2013; 7(6): 1250-3.

3. Human Microbiome Project Consortium. Structure, function and diversity of the healthy human microbiome. Nature. 2012; 486(7402): 207-14.

4. Simón-Soro A, Mira A. Solving the etiology of dental caries. Trends Microbiol. 2015; 23(2):76-82.

5. Fejerskov O. Changing paradigms in concepts on dentalcaries: consequences for oral health care. Caries Res. 2004; 38(3):182-91.

6. Narvai PC. Cárie dentária e flúor: uma relação do século XX. Ciênc Saúde Coletiva. 2000; 5(2):381-92.

7. Kidd EAM, Fejerskov O. The control of disease progression: non-operative treatment. In: Fejerskov $\mathrm{O}$, Kidd EAM (ed.) Dental caries: the disease and its clinical management. 2nd edition. Oxford: Wiley-Blackwell; 2008. p. 251-6.

8. Douglas GV, Ramsdale MP, Vinall-Collier K, Csikar JI. Using high fluoride concentration products in public policy: a rapid review of current guidelines for high fluoride concentration products. Caries Res. 2016; 50(Suppl 1):50-60.

9. Fejerskov O, Cury JA, Tenuta LMA, Marinho V. Fluorides in caries control. In: Fejerskov O, Nyvad B, Kidd EAM, editors. Dental caries: the disease and its clinical management. 3rd edition. Oxford: WileyBlackwell; 2015. p. 245-76.

10. Buzalaf MA, Passan JP, Honorio HM, ten Cate JM. Mechanisms of action of fluoride for caries control. Monogr Oral Sci. 2011; 22(1):97-114.

11. Pakdaman A, Yarahmadi Z, Kharazifard MJ. Selfreported knowledge and attitude of dentists towards prescription of fluoride. J Dent. 2015; 12(8):550-6.

12. Yoder KM, Maupome G, Ofner S, Swigonski NL. Knowledge and use of fluoride among indiana dental professionals. J Public Health Dent. 2007; 67(3): 140-7.

13. Dean HT. Endemic fluorosis and its relation to dental caries. 1938. Nutrition. 1990; 6(6):435-45.

14. Leal SD, Carvalho FS, Carvalho CAP. Conhecimento de alunos do curso de odontologia sobre o uso racional do flúor. Rev Odontol UNESP. 2015; 44(1):51-8.

15. Petersen PE, Lennon MA. Effective use of fluorides for the prevention of dental caries in the 21st century: the WHO approach. Community Dent Oral Epidemiol. 2004; 32(5):319-21.

16. Chaves MM, Frankel JM, Mello C. Fluoração de águas de abastecimento público para prevenção parcial da cárie dentária. Rev Assoc Paul Cir Dent. 1953; 7(2):27-33.

17. Antunes JLF, Narvai PC. Políticas de saúde bucal no Brasil e seu impacto sobre as desigualdades em saúde. Rev Saúde Pública. 2010; 44(2):360-5.

18. Kumar JV. Is water fluoridation still necessary? Adv Dent Res. 2008; 20(1):8-12.

19. Bizerril DO, Almeida JRS, Saldanha KGH, Cabral Filho RE, Almeida MEL. Analysis of fluoride concentration in commercial bottled Waters. Rev Gauch Odontol. 2015; 63(4):461-6.

20. Levy SM, Kritsy MC, Warren JJ. Sources of fluoride intake in children. J Public Health Dent. 1995; 55(1):39-52.

21. Lodi CS, Ramires I, Pessan JP, Neves LT, Buzalaf MAR. Fluoride concentrations in industrialized beverages consumed by children in the city of Bauru, Brazil. J Appl Oral Sci. 2007; 15(3):209-12.

22. Fomon SJ, Ekstrand J, Ziegler EE. Fluoride intake and prevalence of dental fluorosis: trends in fluoride intake with special attention to infants. J Public Health Dent. 2000; 60(1):131-9. 
23. Ammari AB, Bloch-Zupan A, Ashley PF. Systematic review of studies comparing the anti-caries efficacy of children's toothpaste containing $600 \mathrm{ppm}$ of fluoride or less with high fluoride toothpastes of $1.000 \mathrm{ppm}$ or above. Caries Res. 2003; 37(2):85-92.

24. Walsh T, Worthington HV, Glenny AM, Appelbe P, Marinho VC, Shi X. Fluoride toothpastes of different concentrations for preventing dental caries in children and adolescents. Cochrane Database Syst Rev. 2010; 20(1): CD007868.

25. Bansal R, Bolin KA, Abdellatif HM, Shulman JD. Knowledge, attitude and use of fluorides among dentists in Texas. J Contemp Dent Pract. 2012; 13(3):371-5.

26. Ferreira RGLA, Marques RAA, Menezes LMB, Narvai PC. Múltiplos aspectos do uso do flúor em saúde pública na visão de lideranças da área de saúde. Ciênc Saúde Coletiva. 2013; 18(7):2139-46.

27. Lima YBO, Cury JA. Ingestão de flúor por crianças pela água e dentifrício. Rev Saúde Pública. 2001; 35(6): 576-81.

28. Zaror C, Vallejos C, Corsini G, De La Puente C, Velásquez $\mathrm{M}$, Tessada-Sepúlveda $\mathrm{R}$ et al. Revisión sistemática sobre los efectos adversos de la fluoración del agua. Int J Odontostomat. 2015; 9(1):165-71.

29. Petersen PE. Challenges to improvement of oral health in the 21st century - the approach of the WHO Global Oral Health Programme. Int Dent J. 2004; 54 (6 Suppl 1):329-43.

\section{CONFLITO DE INTERESSES}

Os autores declaram não haver conflitos de interesse.

\section{AUTOR PARA CORRESPONDÊNCIA}

Cristiane Alves Paz de Carvalho

capcarvalho@uesb.edu.br

Submetido em 21/03/2018

Aceito em 11/05/2018 